\title{
The effect of anthropogenic factors on rare, endemic plant species in the Ile Alatau
}

\author{
Alibek Ydyrys ${ }^{1,2, *}$, Akerke Serbayeva ${ }^{2}$, Symbat Dossymbetova $^{3}$, Aigul Akhmetova ${ }^{2}$ and Aida \\ Zhuystay $^{2}$ \\ ${ }^{1}$ Al-Farabi Kazakh National University, Biomedical Research Centre, 05004071 al-Farabi Ave, Almaty, \\ Kazakhstan \\ ${ }^{2}$ Al-Farabi Kazakh National University, 05004071 al-Farabi Ave, Almaty, Kazakhstan \\ ${ }^{3}$ Almaty Technological University, 050012 Str. Tole Bi 100, Almaty, Kazakhstan
}

\begin{abstract}
Our study showed that the anthropogenic impact on the flora of the study area, including agricultural activities, is growing every year. This complex research has been conducted in Almaty Province on the 6 populations of the four rare and endemic plant species (Ikonnikovia kaufmanniana, Limonium michelsonii), taking into account the total number, age spectrum. An analysis of the density and age structure of the populations Ikonnikovia kaufmanniana showed that the age range of the population 1 and 2 account for maximum virginal individuals and in the population of 3 generative individuals. The results of the study of the age and condition of life Limonium michelsonii in different parts of the three populations showed that a young virginal (64.6\%) and generative individuals $(23.6 \%)$ and in the population 2, the maximum is in juvenile $(54.5 \%)$ and $(20.49 \%)$ individuals and population 3 maximum occurs at a young virginal $(38.9 \%)$ and $(29.4 \%)$ individuals.
\end{abstract}

\section{Introduction}

One of the most important issues today is the efficient use and conservation of biodiversity while providing safe food, consumer goods and materials. This issue is above all on the agenda of green plants that produce life energy. Plants are not only an important part of the natural environment, but also play a key role in the functioning and formation of the ecosystem.

They are a clear indicator of the state of the environment, a source of nutrients and nutrients for all living organisms on the plane. The research and preservation of biological diversity is a global task nowadays [1]. In assessing the impact on the environment, insufficient attention is paid to the assessment and prevention of damage to rare and endangered plant species listed in the Red Book [2]. Many scientists study rare, endemic, and endangered species with the aim of preservation of such species $[3,4,5]$.

One of the main reasons for the fall of species into the category of rare and endangered is the destruction or complete destruction of the habitats of these species. The negative consequences of human impact on rare and endangered species, depending on a diverse combination of impact factors and specific territorial conditions, are different.

\footnotetext{
* Corresponding author: ydyrys.alibek@gmail.com
} 
It is necessary to separate the processes of changes in biological diversity because of anthropogenic activities from the natural processes of its development. Natural factors should be considered when developing programs for the conservation of biological diversity, but their prevention is impractical, and in most cases is impossible. Anthropogenic factors are prevented, first, by those that most strongly affect biosystems or are critical for them.

Geobotanical criteria are not only sensitive to environmental disturbances, but also the most representative ("physiognomic") ones that best help to trace the zones of the ecological state by size in space and by stages of disturbance in time [6]. Botanical indicators are very specific, since different plant species and different plant communities in different geographical conditions have unequal sensitivity and resistance to disturbing influences and, therefore, the same indicators for qualifying zones of ecological state can vary significantly for different landscapes. At the same time, signs of negative changes at different levels are considered: organismic (phytopathological changes), population (deterioration in species composition and phytocenometric characteristics) and ecosystem (ratio of areas in the landscape).

\section{Materials and Methods}

One of the most pressing issues in the conservation of biodiversity in Kazakhstan is the condition of rare and endemic plant species. The south-eastern part of the country is a dangerous area for rare plant species due to its dense population and industrial, agricultural and border areas. Due to anthropogenic and technical factors, the habitat of rare species is shrinking every day, leading to the extinction of their natural populations. The extinction of a species is, in fact, the disappearance of local populations, which can be represented in nature.

The valuable rare and endemic species of plant in the south-east of Kazakhstan are Limonium michelsonii and Ikonnikovia kaufmanniana (Regel) Lincz. These plants were included into the list of objects that require environmental protection. Three populations of these plants were surveyed during in 2014.

Research work consists of methods of plant-locating by route-reconnaissance, using GPS navigation. Geobotanical descriptions were performed by the conventional methods. The study population was carried out according to the traditional methods of Rabotnov T. A. [7]. The isolation and characterization of age made use of the procedural provisions in the works of Rabotnov T. A. and Uranov A. A. [8]. Therefore, the study of rare plant species at the population level is the most popular and effective method. This 'Population Approach' has an important scientific value, which is illustrated by the fact that it involves a comprehensive study of plant species that make up a particular population. It therefore provides important information about the growth of the production and the ability of rare species of plants to effectively reproduce [9-10].

\section{Results and discussion}

These research were conducted in Almaty region in the mountains Ile Alatau. We investigated three populations of Ikonnikovia kaufmanniana and three populations Limonium michelsonii.

The first population of Ikonnikovia kaufmanniana was found within the Alasa passage of the mountains Toraigyr, $25 \mathrm{~km}$ away from the settlement of Kokpek. The terrain was mostly flat plain with moderate undulating slopes. The soil was gray-brown, rubbly and in places with exposed surface of the tertiary red clays.

The total number of species for the first population of Ikonnikovia kaufmanniana was 409 individual plants: 65 - immature plants; 126 - virginile plants; 109 - young reproductive plants; 36 - mature reproductive plants; 50 - old reproductive plants; 7 - subsenile plants; 16 senile plants and 0 juvenile plants were absent (see table 1 ).. 
The second population of Ikonnikovia kaufmanniana was observed in the area of low mountain range of Sugaty, near the passage of Kokpek , $3 \mathrm{~km}$ away from the settlement Kokpek, In total, 543 plants of Ikonnikovia kaufmanniana were identified within the area of 30 platforms area. Among these plants 2 juvenile plants, 46 - immature plants, 226 - virginile plants, 212 - young reproductive plants, 23 - mature reproductive plants, 24 - old reproductive plants, 2- subsenile plants, and 8 senile were identified. This population was characterized by the presence of plants of all age stages (see table 1).

Table 1. Ontogeny and age composition of Ikonnikovia kaufmanniana in different populations

\begin{tabular}{|c|c|c|c|}
\hline $\begin{array}{l}\text { age composition } \\
\text { (pieces) }\end{array}$ & $1^{\text {st }}$ population & $2^{\text {nd }}$ population & $3^{\text {rd }}$ population \\
\hline No population & 0 & 2 & 3 \\
\hline juvenile & 65 & 46 & 8 \\
\hline immature & 126 & 226 & 72 \\
\hline virginile & 109 & 212 & 95 \\
\hline young reproductive & 36 & 23 & 19 \\
\hline mature reproductive & 50 & 24 & 24 \\
\hline old reproductive & 7 & 2 & 3 \\
\hline subsenile & 16 & 8 & 5 \\
\hline senile & 409 & 543 & 229 \\
\hline total & & & \\
\hline
\end{tabular}

The third population of Ikonnikovia kaufmanniana was found at the foot of low mountains range named Sugety that is along the Almaty-Korgas highway, $10 \mathrm{~km}$ away from the settlement of Nura. Overall, 229 individual plants of Ikonnikovia kaufmanniana were identified within 30 platforms area: 3 - juvenile plants, 8- immature plants, 72 - virginile plants, 95 young reproductive plants, 19 - mature reproductive plants, 24 - old reproductive plants, 3 subsenile plants and 5 senile plants (see table 1).

The fuller age structure was observed for the second and third populations of Ikonnikovia kaufmanniana. The greatest number of individual plants per a site area of Ikonnikovia kaufmanniana was also recorded for the second population and the smallest number of plants was in the third population. The second population also showed the greatest number of individual plants of different ages per site area (see table 1).

Thus, analysis of the data collected for the three natural populations of endemic and endangered species plant Ikonnikovia kaufmanniana using a geobotanical method showed that the areas of its distribution and surface coverage were insignificant. Moreover, distribution of the plant within the studied populations was uneven. Ikonnikovia kaufmanniana grows mainly on the saline clays, variegated ground exposures and stone-gravel slopes at the lower range of mountains ridge.

The first population of Limonium michelsonii was found at the foot of the Aqshoky plateau, $13 \mathrm{~km}$ from the village of Kokpek. The terrain is flat, hilly. The soil is gray, brown, finely sandy, reddish clay of the third epoch. Humidification of the atmosphere.

Table 2. Ontogeny and age composition of Limonium Michelsonii in different populations

\begin{tabular}{|c|c|c|c|}
\hline $\begin{array}{l}\text { age composition } \\
\text { (pieces) }\end{array}$ & $1^{\text {st }}$ population & $2^{\text {nd }}$ population & $3^{\text {rd }}$ population \\
\hline № population & 0 & 39 & 1 \\
\hline juvenile & 0 & 114 & 9 \\
\hline immature & 44 & 152 & 45 \\
\hline virginile & 86 & 345 & 150 \\
\hline young reproductive & 261 & 124 & 100 \\
\hline mature reproductive & 0 & 12 & 14 \\
\hline old reproductive & \multicolumn{2}{|}{} \\
\hline
\end{tabular}




\begin{tabular}{|c|c|c|c|}
\hline subsenile & 0 & 38 & 6 \\
\hline senile & 0 & 10 & 1 \\
\hline total & 391 & 834 & 326 \\
\hline
\end{tabular}

The floristic structure of the first population was 391 individuals of Limonium Michelsonii, from them mature reproductive - 261 plants, young reproductive - 86 plants, virginile - 44 plants and juvenile plants, immature, old reproductive plants, subsenile and senile were absent (see table 1).

The second population was found in the region of the Bartogay reservoir of the East Ile Alatau. In the association of this population the quantity of Limonium Michelsonii consist of 834 individuals plant, of them young reproductive individuals - 345 plants, virginile - 152 plants, mature reproductive individuals - 124 plants, immature - 114 plants, juvenile 39 plants, subsenile - 38 plants, old - 12 plants and senile - 10 plants (see table 1).

The third population of Limonium Michelsonii was found at the bottom of mountains Toraigyr along the Almaty-Narynkol highway. The number of Limonium Michelsonii on registration assaociation made 326 individuals, of them juvenile-1 plants, immature - 9 plants, virginile - 45 plants, young reproductive -150 plants, mature reproductive - 100 plants, old reproductive- 14 plants, subsenile - 6 plants, senile-1 individuals plants. Analysis of the age structure of the populations showed that the age structure of the maximum occurs at mature reproductive plants $(66 \%)$. and in populations of number 2 and 3 on the young reproductive plants $(40-45 \%)$ (see table 1$)$.

\section{Conclusion}

The field work carried out in the eastern part of the Ili Alatau mountains to study three populations of Ikonnikovia kaufmanniana showed that in terms of the age structure, the maximum number of virginal plants was observed in the third population. Among the plant associations, №1, №2, populations were showed higher number of virginal plants, whereas №3 population was showed larger number of young generative plants of Ikonnikovia kaufmanniana. The juvenile plants were not found at all in №1 population. Overall, the observations from this study indicate that growth and distribution of Ikonnikovia kaufmanniana can be considered as normal, with no presence of immediate serious danger to their existence.

In adverse conditions (strong anthropogenic influence, grazing) populations 1 and 3 of Limonium Michelsonii close to a regressive type. Because these populations no juvenile, immature individuals. A population 2 was full members of the mature. Them in the near future are not threatened.

\section{References}

1. Laura J. Pollock, M.J. Louise, Karel Mokany, Dan F. Rosauer, Matthew V. Talluto, Wilfried Thuiller, Protecting Biodiversity (in All Its Complexity): New Models and Methods. Trends in Ecology \& Evolution Available online 22 September (2020)

2. Red Book of Kazakhstan, Alma-Ata, Kazakhstan, Part 2: Plants, (1981)

3. Aigul Akhmetova, Nashtay Mukhitdinov, Alibek Ydyrys. Pakistan Journal of Botany, 47 (2), $511-515(2015)$

4. A.B. Akhmetova, N.M. Mukhitdinov, A. Ydyrys, A.A. Ametov, Z.A. Inelova, M. Öztürk. Journal of Animal and Plant Sciences, 28 (5), 1400-1404 (2018)

5. A. Begenov, N. Mukhitdinov, A. Ametov, S. Nazarbekova, A. Kuatbayev, B. Tynybekov, K. Abidkulova, A. Ydyrys. World Applied Sciences Journal: IDOSI Publications, 30 (1), 105-109 (2014) 
6. A. V.Belov, L.P. Sokolova. Geography and Natural Resources, 30 (2), 119-125 (2009)

7. T.A. Rabotnov, Geobotany, 6, 70-205 (1960)

8. A.A. Uranov, Ontogeny and age composition of populations. Ontogeny and age structure of populations of flowering plants, (Moscow, 1967)

9. K. Abidkulova, N. Mukhitdinov, A. Ametov, A. Ydyrys, N. Kudajbergenova. The age structure of the cenopopulations of rare endemic plant Ikonnikovia kaufmanniana from Kazakhstan, 7th Planta Eur. Conf. Abstracts. Ortodox Academy of Crete, Kolympary (2014)

10. A. Ydyrys, N. Mukhitdinov, A. Ametov, B. Tynybekov, A. Akhmetova, K. Abidkulova. World Appl Sc J. 26 (7), 934-940 (2013) 